\title{
Vascular mechanisms of cognitive impairment: roles of hypertension and subsequent small vessel disease under sympathetic influences
}

\author{
Ichiro Akiguchi and Yasumasa Yamamoto \\ Hypertension Research (2010) 33, 29-31; doi:10.1038/hr.2009.189; published online 13 November 2009
}

$\mathrm{M}$ ild cognitive impairment (MCI) and vascular cognitive impairment are clinically important in the development of Alzheimer disease $(\mathrm{AD})^{1}$ and Binswanger disease/vascular dementia. ${ }^{2,3}$ The vascular mechanisms of $\mathrm{MCI} /$ vascular cognitive impairment, as well as $\mathrm{AD}$ with vascular factors, are likely chronic cerebral ischemia due to both hypertensive lipohyalinotic small artery disease and arteriolar-capillary fibrohyalinosis with subsequent dysfunction of the blood-brain barrier. ${ }^{4,5}$ These may ultimately cause multiple lacunes in the basal ganglia and the white matter, as well as white matter rarefaction by alteration in the glia and axons. $^{4}$

Sympathetic nerve terminals exist not only in the innermost part of the adventitia, but also in the outer layer of the tunica media in human cerebral arteries. ${ }^{6}$ Furthermore, the density of sympathetic terminals in cerebral arterial walls makes up over $30 \%$ of the total nerve terminals. ${ }^{7}$ These may have roles in the development of angionecrosis/medial necrosis under excessive neurogenic control to smooth muscle layers by repeated arterial constrictions, while maintaining autoregulation of perfusion pressure under persistent hypertension. Thus, earthenware pipe-like subpial medial necrosis and medullary arteriolosclerosis accompanying diffuse white matter lesions in vascular cognitive impairment/Binswanger disease brains appear. ${ }^{8,9}$

Dr I Akiguchi is at the Center of Neurological and Cerebrovascular Disease, Koseikai Takeda Hospital, 841-5 Higashishiokoji-cho, Shimogyo-ku, Kyoto 6008558, Japan; Y Yamamoto is at the Department of Neurology, Kyoto Second Red Cross Hospital, Kyoto, Japan.

E-mail: akiguchi@kuhp.kyoto-u.ac.jp
Moreover, blood-brain barrier alters with aging and even in some normal brain structures such as the olfactory bulb, hippocampus and periventricular areas, ${ }^{10-12}$ and bloodbrain barrier dysfunctions with the development of capillary collagenosis have been revealed not only in Binswanger disease brains, ${ }^{13,14}$ but also spontaneously hypertensive rats and a rat model of chronic cerebral hypoperfusion. ${ }^{15,16}$ Recently, it has been shown that the intra-cranial capillary diameter is regulated by pericyte contraction under noradrenergic and purinergic neurotransmitter influences. ${ }^{17}$ All the above findings suggest that a failure in autonomic control of cerebral circulation and damage in blood-brain barrier under untreated hypertension have significant roles in the pathogenesis of $\mathrm{MCI} /$ vascular cognitive impairment.

The relationship, however, between hypertension and cognitive impairment has long been debated and still remains controversial. The majority of studies suggest that elevated blood pressure (BP) is associated with cognitive decline. ${ }^{18}$ Longitudinal studies examining midlife hypertension have reported $\mathrm{BP}$ as a risk factor for dementia, suggesting its association with late-life atherosclerosis and vascular mechanisms of dementia. The Honolulu-Asia Aging Study-which tracked 2505 men, ages ranging from 71 to 93 years old, who were dementia-free over a mean of 5.1 years-demonstrated that dementia was significantly associated with high systolic BP, but not with pulse pressure. ${ }^{19}$ Hypertension may be expected to predispose patients to the development of small vessel diseases, such as silent lacunar infarcts or white matter lesions, leading to cognitive impairment and finally, dementia. $^{20}$ Conversely, it has also been reported that relatively low $\mathrm{BP}$ is related to higher prevalence of dementia. The crosssectional study of the Kungsholmen project-including 1642 subjects, aged 75-101 years-demonstrated that both systolic and diastolic BP were inversely related to prevalence of dementia in elderly people at baseline. $^{21}$ They further performed a 6-year follow-up study for community-based dementia-free cohort of 1270 subjects. Subjects with very high systolic BP (>180 vs. $141-180 \mathrm{~mm} \mathrm{Hg}$ ) and extremely low diastolic BP ( $\leqslant 65$ vs. $66-90 \mathrm{~mm} \mathrm{Hg}$ ) showed a significant association with subsequent development of $\mathrm{AD}$ or other dementias. ${ }^{22}$

The Bronx Aging Study is a prospective study of 488 community-dwelling elderly individuals-over the age of 75 , dementiafree at baseline, and followed at 12- to 18 month intervals. Low diastolic BP significantly influenced risk of developing $\mathrm{AD}$, but not vascular dementia. ${ }^{23}$ It can be postulated that $\mathrm{BP}$ changes in $\mathrm{AD}$ cause degeneration of neurons or reduction of the neurotransmitter pool, which regulate BP. Low BP may thus be a consequence of dementia, as neuronal loss itself may lower BP, particularly in $\mathrm{AD}$. This mechanism may be reinforced by the dysfunction in the autonomic nervous system observed in patients with $\mathrm{AD}^{24}$ On the other hand, low BP may be an anticipatory factor for dementia if perfusion pressure decreases due to advanced atherosclerosis or cerebral dysautoregulation. Experimental cerebral hypoperfusion is reported to be associated with overexpression of $\beta$-amyloid precursor protein. ${ }^{25}$ In follow-up study of lacunar infarction, BP tended to decrease in those who developed dementia, whereas BP tended 
to increase over time in patients with a fair outcome. ${ }^{26}$ Autonomic functions, including sympathetic activity, might have a role in changes in BP during the course of cerebral infarction involving the autonomic nervous system and these fiber connections in spontaneously hypertensive rats ${ }^{27}$ and hypertensive patients. ${ }^{28}$

Ambulatory BP monitoring is expected to evaluate the course of cognitive worsening in hypertensive patients than casual BP monitoring. On this issue, Guo Haiyan et al. ${ }^{21}$ presented the valuable finding that abnormal nocturnal BP profile is associated with MCI. Although clinic BP was not significantly different between patients with and without MCI, 24-h nighttime BP level and BP values-especially nighttime systolic $\mathrm{BP}$ were significantly higher in those with $\mathrm{MCI}$ than those without $(P=0.008)$. Moreover, riser pattern showed strongest association with MCI, followed by non-dipper and extreme dipper. High absolute systolic BP and non-dipping status were strong indicators for reduced brain matter volume and cognitive impairment. ${ }^{29}$ We prospectively studied the relationship between ambulatory BP monitoring values, stroke recurrence and subsequent cognitive decline (Figure 1). ${ }^{30}$ High nighttime BP and/or non-dipping status were found to be significantly associated with both stroke recurrence and dementia progression. The Uppsala followup study consisted of 999 seventy-year-old men, because high diastolic BP at baseline examination at the age of 50 years was revealed to be related to impaired cognitive performance 20 years later-even after exclusion of men with a previous stroke. ${ }^{31}$ Also, cross-sectional measurements at the age of 70 years showed that high 24-h diastolic BP and a non-dipping nocturnal BP pattern, as well as insulin resistance and diabetes, were related to low cognitive function.

A limitation of the study from Guo Haiyan et al., ${ }^{21}$ however, is that brain imaging study was lacking. Cognitive impairment has consistently been reported to be strongly associated with brain structural abnormalities; abnormalities such as brain atrophy, asymptomatic infarcts and white matter lesions. It has been suggested that progression of white matter lesions, in particular, correlate with cognitive impairment, not only in patients with cerebrovascular disease history, ${ }^{32}$ but also in healthy elderly people. ${ }^{33}$ The absence of nocturnal systolic BP decline, particularly riser pattern, was also strongly correlated with extensive white matter lesions. ${ }^{34}$ We performed a long-term follow-up study of 177 patients with lacunar infarct for a mean of 8.9

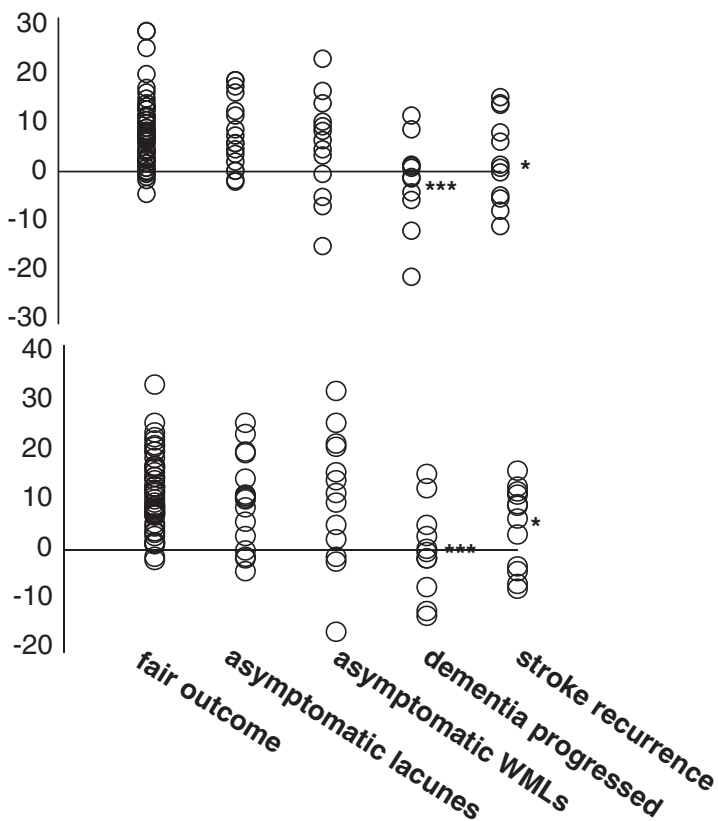

Figure 1 One hundred and five patients with lacunar infarcts were tracked for a mean of 3.2 years. Patients underwent repeated magnetic resonance imaging and 24-h blood pressure monitoring under treatment. The vertical scale indicates a percentage of nocturnal blood pressure decline. The upper figure shows systolic pressure decline. The lower figure shows diastolic pressure decline. Value for each patient is shown by circle according to five different outcomes. Patients with subsequent development of dementia and stroke recurrence showed significant association with reduced nocturnal blood pressure decline $\left(* * * P<0.001,{ }^{*} P<0.05\right)$.

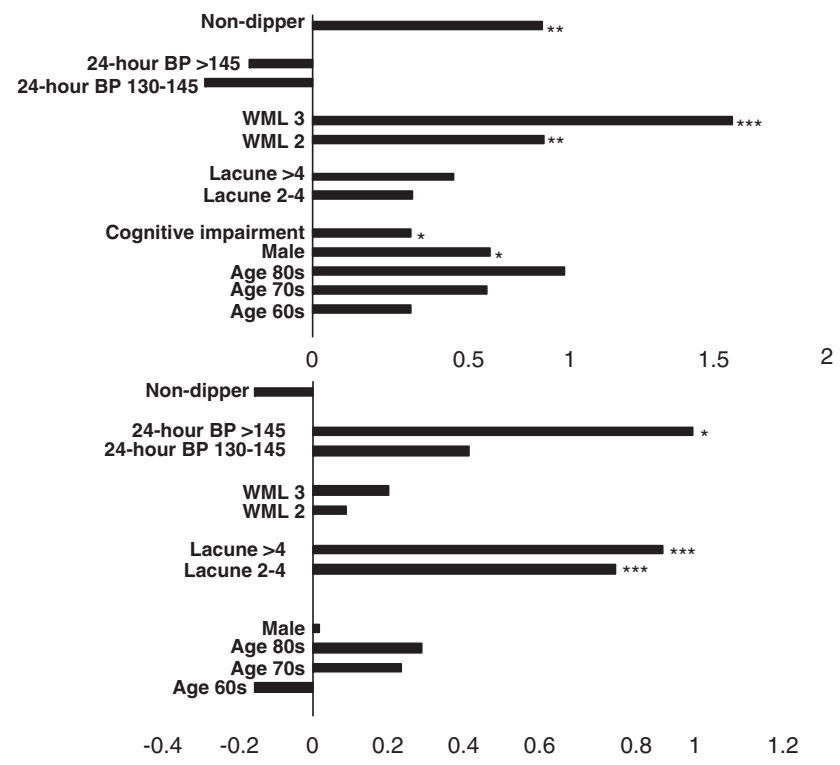

Figure 2 One hundred and seventy seven patients with lacunar infarct were tracked for a mean of 8.9 years of follow-up. Predictors for stroke recurrence (lower half of figure) and subsequent development of dementia appear to differ (upper half). Male gender, confluent diffuse white matter lesions and nondipping status were independent predictors for subsequent development of dementia, whereas diabetes mellitus (not shown), multiple lacunae and high 24-h systolic blood pressure were independent predictors for stroke recurrence $\left({ }^{* *} P<0.001,{ }^{* *} P<0.01,{ }^{*} P<0.05\right)$.

years, using magnetic resonance imaging and ambulatory BP monitoring (Figure 2). ${ }^{35}$ Male gender, confluent diffuse white matter lesions and non-dipping status were independent predictors for subsequent development of dementia. We further found in cross-sectional study of 200 patients with lacunar infarction that non-dipper and reversed dipper, as well 
as male gender and extensive white matter lesions, were independently associated with cognitive impairment. ${ }^{36}$ High nighttime BP and/or non-dipping status, particularly reversed dipper, were significantly associated with extensive white matter lesions.

The underlying mechanism of riser $\mathrm{BP}$ or extreme dipper BP pattern is uncertain. Grassi et al., ${ }^{37}$ using measurement of muscle sympathetic nerve traffic, observed that sympathetic activation has a major role in $\mathrm{BP}$ dipping mechanism, and riser status is more strongly correlated with a sympathetic activation than any dipping status. They suggested that increased prevalence of hypertensive target organ damage or higher incidence of cerebro-cardiovascular events described in non-dipping status may depend, not just on the 24-h BP overload accompanying higher nocturnal BP values, but also on the increased sympathetic activation. Kario et al., ${ }^{38}$ on the other hand, investigated the relationship between ambulatory $\mathrm{BP}$ monitoring and postural BP variation in elderly hypertensive patients. They showed that abnormal diurnal BP variation closely related to postural BP variation with extreme dippers showing orthostatic hypertension and non-dippers showing orthostatic hypotension. Moreover, the orthostatic BP increase was selectively eliminated by $\alpha$-adrenergic blocking-indicating that $\alpha$-adrenergic activity is the predominant mechanism of orthostatic hypertension. ${ }^{39}$ Morning BP may be closely associated with $\alpha$-adrenergic activity. Thus, extreme dipper may potentially facilitate the process of cognitive impairment by morning hypertension, rather than nocturnal excessive BP decline. ${ }^{40}$ In any event, it should be noted that a high prevalence of cognitive impairment was observed most frequently in the riser pattern. The vascular pathophysiologic mechanisms of riser pattern and its treatment need to be further explored.

1 Petersen RC. Early diagnosis of Alzheimer's disease: is $\mathrm{MCl}$ too late? Curr Alzheimer Res 2009; 6: 324-330.

2 O'Brien JT, Erkinjuntti T, Reisberg B, Roman GC, Sawada T, Pantoni L, Bowler JV, Ballard C, DeCarli C, Gorelick PB, Rockwood K, Burns A, Gauthier S, DeKosky ST. Vascular cognitive impairment. Lancet Neurol 2003; 2: 89-98.

3 Roman GC, Erkinjuntti T, Wallin A, Pantoni L, Chui HC. Subcortical ischaemic vascular dementia. Lancet Neurol 2002; 1: 426-436.

4 Akiguchi I, Tomimoto H, Suenaga T, Wakita H, Budka $\mathrm{H}$. Alterations in glia and axons in the brains of Binswanger's disease patients. Stroke 1997; 28: 1423-1429.
5 Tomimoto H, Akiguchi I, Suenaga T, Nishimura M, Wakita $\mathrm{H}$, Nakamura S, Kimura J. Alterations of the blood-brain barrier and glial cells in white matter lesions in cerebrovascular and Alzheimer's disease patients. Stroke 1996; 27: 2069-2074.

6 Akiguchi I, Fukuyama H, Kameyama M, Koyama T, Kimura $\mathrm{H}$, Maeda T. Sympathetic nerve terminals in the tunica media of human superficial temporal and middle cerebral arteries; wet histofluorescence. Stroke 1983; 14: 62-66.

7 Oka N, Akiguchi I, Matsubayashi K, Kameyama M, Maeda T, Kawamura J. Density of sympathetic nerve terminals in human superficial temporal arteries; potassium permanganate fixation and monoamine oxidase histochemistry. Stroke 1987; 18: 229-233.

8 Furuta A, Ishii N, Nishihara Y, Horie A. Medullary arteries in aging and dementia. Stroke 1991; 22: 442-446.

9 Tanoi Y, Okeda R, Budka R. Binswanger's encephalopathy: serial sections and morphometry of the cerebral arteries. Acta Neuropathol (Berl) 2000; 100: 347-355.

10 Ueno M, Akiguchi I, Hosokawa M, Sakamoto H, Shinnou M, Takemura M, Higuchi K. Ultrastructural and permeability features of microvessels in the olfactory bulbs of SAM mice. Acta Neuropathol (Berl) 1998; 96: 261-270.

11 Ueno M, Akiguchi I, Hosokawa M, Shinnou M, Sakamoto H, Takemura M, Higuchi K. Age-related changes in the brain transfer of blood-borne horseradish peroxidase in the hippocampus of senescenceaccelerated mouse (SAM). Acta Neuropathol (Berl) 1997; 93: 233-240.

12 Ueno M, Akiguchi I, Hosokawa M, Kotani H, Kanenishi K, Sakamoto H. Blood-brain barrier permeability in the periventricular areas of the normal mouse brain. Acta Neuropathol (Berl) 2000; 99: 385-392.

13 Akiguchi I, Tomimoto H, Suenaga T, Wakita H, Budka H. Blood-brain barrier dysfunction in Binswanger's disease; an immunohistochemical study. Acta Neuropathol (Berl) 1998; 95: 78-84.

14 Lin J-X, Tomimoto H, Akiguchi I, Matsuo A, Wakita H, Shibasaki $\mathrm{H}$, Budka $\mathrm{H}$. Vascular cell components of the medullary arteries in Binswanger's disease: a morphometric and immunoelectron microscopic study. Stroke 2000; 31: 1838-1842.

15 Ueno $M$, Sakamoto $H$, Tomimoto $H$, Akiguchi I, Onodera M, Huang CL, Kanenishi K. Blood-brain barrier is impaired in the hippocampus of young adult spontaneously hypertensive rats. Acta Neuropathol (Berl) 2004; 107: 532-538.

16 Ueno M, Tomimoto $H$, Akiguchi I, Wakita H, Sakamoto $\mathrm{H}$. Blood-brain barrier disruption in white matter lesions in a rat model of chronic cerebral hypoperfusion. J Cereb Blood Flow Metab 2002; 22 : 97-104.

17 Peppiatt CM, Howarth C, Mobbs P, Attwell D. Bidirectional control of CNS capillary diameter by pericytes. Nature 2006; 443: 700-704.

18 Tsivgoulis G, Alexandrov AV, Wadley VG, Unverzagt FW Go RC, Moy CS, Kissela B, Howard G. Association of higher diastolic blood pressure levels with cognitive impairment. Neurology 2009; 73: 589-595.

19 Freitag MH, Peila R, Masaki K, Petrovitch H, Ross GW, White LR, Launer LJ. Midlife pulse pressure and incidence of dementia: the Honolulu-Asia Aging Study. Stroke 2006; 37: 33-37.

20 Glynn RJ, Beckett LA, Hebert LE, Morris MC, Scherr PA, Evans DA. Current and remote blood pressure and cognitive decline. JAMA 1999; 281: 438-445.

21 Guo Z, Viitanen M, Fratiglioni L, Winblad B. Low blood pressure and dementia in elderly people: the Kungsholmen project. $\mathrm{Br}$ Med J 1996; 312: 805-808.

22 Qiu C, von Strauss E, Fastbom J, Winblad B, Fratiglioni L. Low blood pressure and risk of dementia in the Kungsholmen project: a 6-year follow-up study. Arch Neurol 2003; 60: 223-228.
23 Verghese J, Lipton RB, Hall CB, Kuslansky G, Katz MJ. Low blood pressure and the risk of dementia in very old individuals. Neurology 2003; 61: 1667-1672.

24 Nakamura S, Takemura M, Ohnishi K, Suenaga T, Nishimura M, Akiguhci I, Kimura J, Kimura T. Loss of large neurons and occurrence of neurofibrillary tagles in the tuberomammillary nucleus of patients with Alzheimer's disease. Neurosci Lett 1993; 151: 196-199.

25 Shi J, Yang SH, Stubley L, Day AL, Simpkins JW. Hypoperfusion induces overexpression of beta-amyloid precursor protein mRNA in a focal ischemic rodent model. Brain Res 2000; 853: 1-4.

26 Yamamoto Y, Akiguchi I, Oiwa K, Hayashi M, Imai K. Twenty-four-hour blood pressure changes in the course of lacunar disease. Cerebrovasc Dis 2001; 11: 100-106.

27 Akiguchi I, Horie R, Yamori Y. Role of central aminergic febers in experimental cerebral ischemia in strokeprone SHR; relation to anesthetic effect. Stroke 1980; 11: 383-389.

28 Yamamoto Y, Akiguchi I, Oiwa K, Satoi H, Kimura J. Diminished nocturnal blood pressure decline and lesion site in cerebrovascular disease. Stroke 1995; 26: 829-833.

29 Nagai M, Hoshide S, Ishikawa J, Shimada K, Kario K. Ambulatory blood pressure as an independent determinant of brain atrophy and cognitive function in elderly hypertension. J Hypertens 2008; 26: 1548-1550.

30 Yamamoto Y, Akiguchi I, Oiwa K, Hayashi M, Kimura J. Adverse effect of nighttime blood pressure on the outcome of lacunar infarct patients. Stroke 1998; 29: 570-576.

31 Kilander L, Nyman H, Boberg M, Hansson L, Lithell H. Hypertension is related to cognitive impairment: a 20-year follow-up of 999 men. Hypertension 1998; 31: 780-786.

32 Dufouil C, Godin O, Chalmers J, Coskun O, MacMahon S, Tzourio-Mazoyer N, Bousser MG, Anderson C, Mazoyer B, Tzourio C, PROGRESS MRI Substudy Investigators. Severe cerebral white matter hyperintensities predict severe cognitive decline in patients with cerebrovascular disease history. Stroke 2009; 40: 2219-2221.

33 Silbert LC, Howieson DB, Dodge H, Kaye JA. Cognitive impairment risk: white matter hyperintensity progression matters. Neurology 2009; 73: 120-125.

34 Sander D, Winbeck K, Klingelhöfer J, Conrad B. Extent of cerebral white matter lesions is related to changes of circadian blood pressure rhythmicity. Arch Neurol 2000; 57: 1302-1307.

35 Yamamoto Y, Akiguchi I, Oiwa K, Hayashi M, Kasai T, Ozasa K. Twenty-four-hour blood pressure and MRI as predictive factors for different outcomes in patients with lacunar infarct. Stroke 2002; 33: 297-305.

36 Yamamoto Y, Akiguchi I, Oiwa K, Hayashi M, Ohara T, Ozasa $\mathrm{K}$. The relationship between $24-\mathrm{h}$ blood pressure readings, subcortical ischemic lesions and vascular dementia. Cerebrovasc Dis 2005; 19: 302-308.

37 Grassi G, Seravalle G, Quarti-Trevano F, Dell'Oro R, Bombelli M, Cuspidi C, Facchetti R, Bolla G. Mancia Adrenergic, metabolic, and reflex abnormalities in reverse and extreme dipper hypertensives. Hypertension 2008; 52: 797-798.

38 Kario K, Eguchi K, Nakagawa Y, Motai K, Shimada K. Relationship between extreme dippers and orthostatic hypertension in elderly hypertensive patients. Hypertension 1998; 31: 77-82.

39 Kario K, Eguchi K, Hoshide S, Hoshide Y, Umeda Y, Mitsuhashi T, Shimada K. U-curve relationship between orthostatic blood pressure change and silent cerebrovascular disease in elderly hypertensives: orthostatic hypertension as a new cardiovascular risk factor. J Am Coll Cardiol 2002; 40: 133-141.

40 Kario K, Pickering TG, Umeda Y, Hoshide S, Hoshide Y, Morinari M, Murata M, Kuroda T, Schwartz JE, Shimada K. Morning surge in blood pressure as a predictor of silent and clinical cerebrovascular disease in elderly hypertensives: a prospective study. Circulation 2003; 107: 1401-1406. 